\title{
Involvement of the RNA-binding protein ARE/poly(U)-binding factor 1 (AUF1) in the cytotoxic effects of proinflammatory cytokines on pancreatic beta cells
}

\author{
E. Roggli $\cdot$ S. Gattesco $\cdot$ A. Pautz $\cdot$ R. Regazzi
}

Received: 17 May 2011 / Accepted: 7 November 2011 /Published online: 13 December 2011

(C) Springer-Verlag 2011

\begin{abstract}
Aims/hypothesis Chronic exposure of pancreatic beta cells to proinflammatory cytokines leads to impaired insulin secretion and apoptosis. ARE/poly(U)-binding factor 1 (AUF1) belongs to a protein family that controls mRNA stability and translation by associating with adenosine- and uridine-rich regions of target messengers. We investigated the involvement of AUF1 in cytokine-induced beta cell dysfunction.

Methods Production and subcellular distribution of AUF1 isoforms were analysed by western blotting. To test for their role in the control of beta cell functions, each isoform was overproduced individually in insulin-secreting cells. The contribution to cytokine-mediated beta cell dysfunction was evaluated by preventing the production of AUF1 isoforms by RNA interference. The effect of AUF1 on the production of potential targets was assessed by western blotting.

Results MIN6 cells and human pancreatic islets were found to produce four AUF1 isoforms ( $\mathrm{p} 42>\mathrm{p} 45>\mathrm{p} 37>\mathrm{p} 40$ ). AUF1 isoforms were mainly localised in the nucleus but were partially translocated to the cytoplasm upon exposure of beta cells to cytokines and activation of the ERK pathway. Overproduction of AUF1 did not affect glucose-induced
\end{abstract}

Electronic supplementary material The online version of this article (doi:10.1007/s00125-011-2399-7) contains peer-reviewed but unedited supplementary material, which is available to authorised users.

E. Roggli $\cdot$ S. Gattesco $\cdot$ R. Regazzi $(\bowtie)$

Department of Cell Biology and Morphology,

Faculty of Biology and Medicine, University of Lausanne,

Rue du Bugnon 9,

CH-1005 Lausanne, Switzerland

e-mail: Romano.Regazzi@unil.ch

\section{A. Pautz}

Department of Pharmacology, University Medical Center of the Johannes Gutenberg University Mainz,

Mainz, Germany insulin secretion but promoted apoptosis. This effect was associated with a decrease in the production of the antiapoptotic proteins, B cell leukaemia/lymphoma 2 (BCL2) and myeloid cell leukaemia sequence 1 (MCL1). Silencing of AUF1 isoforms restored the levels of the anti-apoptotic proteins, attenuated the activation of the nuclear factor- $\mathrm{kB}$ (NFKB) pathway, and protected the beta cells from cytokineinduced apoptosis.

Conclusions/interpretation Our findings point to a contribution of AUF1 to the deleterious effects of cytokines on beta cell functions and suggest a role for this RNA-binding protein in the early phases of type 1 diabetes.

Keywords AUF1 - Apoptosis · Cytokine - Diabetes ·

Heterogeneous nuclear ribonucleoprotein D - Insulin · Islet . RNA $\cdot$ Secretion
Abbreviations
3'-UTR 3'-Untranslated region
AUBP AU-rich binding protein
AUF1 ARE/poly(U)-binding factor 1
BCL2 B cell leukaemia/lymphoma 2
CCL2 Chemokine (C-C motif) ligand 2
CXCL2 Chemokine (C-X-C motif) ligand 2
EGFP Enhanced green fluorescent protein
ERK Extracellular regulated MAPK
GFP Green fluorescent protein
hGH Human growth hormone
I $\mathrm{KB} \alpha \quad$ Inhibitor of $\mathrm{kB}$
iNOS Inducible nitric oxide synthase
JNK c-Jun N-terminal kinase
MAPK Mitogen-activated protein kinase
MCL1 Myeloid cell leukaemia sequence 1
MCP1 Monocyte chemotactic protein 1
MIP2 Macrophage inhibitor protein 2 
NFKB Nuclear factor- $k B$

qRT-PCR Quantitative RT-PCR

siRNA Small interfering RNA

\section{Introduction}

Type 1 diabetes is an autoimmune disease characterised by a progressive loss of pancreatic beta cells. Insulin, the hormone produced by these cells, plays an essential role in the maintenance of blood glucose homeostasis. During the autoimmune attack, macrophages and lymphocytes infiltrate pancreatic islets and release proinflammatory cytokines with a major impact on the expression of key beta cell genes leading to defective insulin secretion and sensitisation to apoptosis [1,2].

Most studies investigating the causes of beta cell dysfunction during the early phases of type 1 diabetes have focused on the role of signalling cascades culminating in the activation of transcription factors [1], but, so far, the potential impact of cytokines on mRNA stability has been poorly investigated. Several RNA-binding proteins are known to bind to specific sequences located on the 3'-untranslated region (3'-UTR) of target mRNAs. A family of RNAbinding proteins called AU-rich (ARE)-binding proteins (AUBPs) interacts specifically with adenosine- and uridine-rich regions located in the $3^{\prime}$-UTR of target mRNAs [3]. Under resting conditions, AUBPs are principally located in the nucleus [4] but, upon stimulation, translocate to the cytoplasm and bind to their targets, leading to mRNA protection, stabilisation, degradation or inhibition of messenger translation [5]. AUF1 (ARE/poly(U)-binding factor 1) [6], also known as hnRNP-D (heterogeneous nuclear ribonucleoprotein $\mathrm{D}$ ), was originally identified as a protein that binds and induces the destabilisation of the mRNAs encoding c-myc and granulocyte-macrophage colony-stimulating factor [7]. AUF1 was later reported to affect the stability of a large variety of mRNAs involved in inflammation, cell cycle control or apoptosis $[8,9]$. Although the destabilising function of AUF1 is well documented, some studies suggest that the protein can also exert a positive effect on mRNA stability [10].

Four different isoforms of AUF1 resulting from differential splicing of exons 2 and 7 have been described: p37, p40, p42 and $\mathrm{p} 45$ [11]. The production of these isoforms varies between cell types and developmental stages and can be modified in response to different stimuli [12]. Moreover, AUF1 isoforms are subjected to post-translational modifications that affect the activation state of the RNA-binding protein in a cell-type and treatment-dependent manner [13, 14].

Since many proteins involved in stress and immune responses or in cellular growth are encoded by mRNAs containing ARE sequences, AUF1 is a good candidate for mediating the alterations in gene expression underlying the impairment in beta cell activities observed in the presence of proinflammatory cytokines.

The aim of this study was to investigate the possible involvement of AUF1 in cytokine-mediated beta cell dysfunction and in the development of type 1 diabetes. We found that AUF1 is indeed activated upon exposure to cytokines and contributes to beta cell apoptosis elicited by these proinflammatory mediators.

\section{Methods}

Chemicals The extracellular regulated MAP kinase (ERK) inhibitor, PD98059, was obtained from CalbiochemNovabiochem (San Diego, CA, USA). The c-Jun N-terminal kinase (JNK) inhibitor, SP600125, was from Enzo Life Sciences (Plymouth Meeting, PA, USA). IL- $1 \beta$ and the p38 mitogen-activated protein kinase (MAPK) inhibitor, SB 239063, were purchased from Sigma (Buchs, Switzerland). Recombinant mouse IFN $\gamma$ was obtained from R\&D Systems (Minneapolis, MN, USA), and TNF $\alpha$ from Alexis Corporation (Lausen, Switzerland). Hoechst 33342 was purchased from Invitrogen (Carlsbad, CA, USA).

Culture and transfection of insulin-secreting cell lines and human pancreatic islets The insulin-secreting cell line, MIN6 clone B1 [15], was cultured at a density of $1.5 \times 10^{5}$ cells $/ \mathrm{cm}^{2}$ in DMEM/Glutamax medium (Invitrogen) supplemented with $15 \% \mathrm{FCS}, 50 \mathrm{IU} / \mathrm{ml}$ penicillin, $50 \mu \mathrm{g} / \mathrm{ml}$ streptomycin and $70 \mu \mathrm{mol} / 1 \beta$-mercaptoethanol. The insulinproducing cell line, INS-1E [16], was cultured at the same density as MIN6 cells in RPMI 1640 (Invitrogen) supplemented with $10 \%$ FCS, $50 \mathrm{IU} / \mathrm{ml}$ penicillin, $50 \mu \mathrm{g} / \mathrm{ml}$ streptomycin, $1 \mathrm{mmol} / \mathrm{l}$ sodium pyruvate and $50 \mu \mathrm{mol} / \mathrm{l}$ $\beta$-mercaptoethanol.

Transient transfections of MIN6 and INS-1E cells were performed with Lipofectamine 2000 (Invitrogen) following the instructions provided by the manufacturer. For a $24-w e l l$ plate, 60 pmol small interfering RNA (siRNA) duplexes and $0.8 \mu \mathrm{g}$ plasmids were used.

Human pancreatic islets were provided by the Cell Isolation and Transplantation Center at the University of Geneva, School of Medicine, thanks to the Islets for Research distribution programme of the European Consortium for Islet Transplantation (ECIT) sponsored by the Juvenile Diabetes Research Foundation. The purity of islet preparations used for this study ranged from $80 \%$ to $95 \%$, and the samples contained $51 \pm 7 \% \quad(\operatorname{mean} \pm \mathrm{SD})$ insulin-positive cells, as revealed by immunofluorescence analysis using an antibody against insulin (Linco Research, St Charles, MO, USA). The islets were cultured in CMRL medium (Invitrogen) 
supplemented with $10 \% \mathrm{FCS}, 100 \mathrm{IU} / \mathrm{ml}$ penicillin, $100 \mu \mathrm{g} / \mathrm{ml}$ streptomycin, $2 \mathrm{mmol} / \mathrm{l}$ L-glutamine and $250 \mu \mathrm{mol} / 1$ HEPES. Islet cell monolayers were prepared by treating the islets for 7-9 min with trypsin $(0.25 \mathrm{mg} / \mathrm{ml}) /$ EDTA at $37^{\circ} \mathrm{C}$. The trypsinisation was terminated by adding serum-containing culture medium. The cells were seeded at a density of $5.5 \times 10^{4}$ cells $/ \mathrm{cm}^{2}$. Human islet cells were transfected using the same conditions as used for MIN6 cells.

AUF1 overproduction and downregulation To experimentally increase AUF1 levels, MIN6 cells were transiently transfected with plasmids expressing enhanced green fluorescent protein (EGFP)-labelled constructs of each individual AUF1 isoform [17]. Reduction of the level of the selected isoforms was achieved using siRNA duplexes directed against: exon 2, targeting p 45 and p $40\left(\right.$ siAUF $\left.^{\mathrm{p} 45 \mathrm{p} 40}\right)$; exon 7 , targeting $\mathrm{p} 45$ and $\mathrm{p} 42$ (siAUF1 $1^{\mathrm{p} 45 \mathrm{p} 42}$ ); and a sequence astride exon 3 and 4 , targeting all isoforms ( $\left(\operatorname{siAUF}^{1 \text { all }}\right.$ ). The sequences were the following: $\operatorname{siAUF} 1^{\mathrm{p} 45 \mathrm{p} 40}, 5^{\prime}-\mathrm{ACU} C \mathrm{CU}$ CCC CAC GAC ACA CTT-3'; siAUF $1^{\mathrm{p} 45 \mathrm{p} 42}, 5^{\prime}$-UCA AGG CUA UGG CAA CUA UTT-3'; and siAUF1 ${ }^{\text {all }}, 5^{\prime}$-AGA AAG AUC UGA AGG ACU ATT-3'. An siRNA duplex directed against green fluorescent protein (GFP; 5'-GAC GUA AAC GGC CAC AAG UUC-3'), which has no effect on pancreatic beta cell functions, was used as control.

Analysis of the expression of protein-coding genes Total RNA extraction was performed with the RNeasy mini kit (Qiagen, Hilden, Germany). Conventional quantitative RTPCR (qRT-PCR) was carried out as described previously [18]. Real-time PCRs were performed on a Bio-Rad MyiQ Single-Color Real-Time PCR Detection System (Bio-Rad Laboratories, Hercules CA, USA). The list of primers can be found in electronic supplementary material (ESM) Table 1. Samples were tested in triplicate, and the results were normalised using cDNA amplified with $18 \mathrm{~S}$ primers in the same samples.

Secretion assay For assessment of the secretory capacity, MIN6 cells $\left(2 \times 10^{5}\right)$ plated in 24-well dishes were transiently co-transfected with AUF1-overexpressing plasmids and with a construct encoding the human growth hormone (hGH) (pXGH5; Nichols Institute Diagnostics, San Juan Capistrano, CA, USA). After $72 \mathrm{~h}$, the cells were washed and preincubated for $30 \mathrm{~min}$ in Krebs buffer $(127 \mathrm{mmol} / 1 \mathrm{NaCl}$, $4.7 \mathrm{mmol} / 1 \mathrm{KCl}, 1 \mathrm{mmol} / \mathrm{l} \mathrm{CaCl} 2,1.2 \mathrm{mmol} / 1 \mathrm{KH}_{2} \mathrm{PO}_{4}$, $1.2 \mathrm{mmol} / 1 \mathrm{MgSO}_{4}, 5 \mathrm{mmol} / 1 \mathrm{NaHCO}_{3}, 0.1 \% \mathrm{BSA}$ and $25 \mathrm{mmol} / \mathrm{l}$ HEPES, pH 7.4) containing $2 \mathrm{mmol} / 1$ glucose. The medium was then discarded, and the cells were incubated for $45 \mathrm{~min}$ in either the same buffer (basal condition) or Krebs buffer containing $20 \mathrm{mmol} / \mathrm{l}$ glucose (stimulatory condition). After collection of the supernatant fractions, the cells were lysed in PBS containing $0.5 \%$ Triton X-100 to evaluate total cellular hGH content. The amount of hGH in the samples was assessed using an hGH ELISA kit (Roche Diagnostics, Rotkreuz, Switzerland). The same was performed for measurement of insulin secretion except that the cells were not co-transfected with hGH and the cells were lysed in ethanol/acid $(75 \%$ ethanol, $1.5 \% \mathrm{HCl}$ and $23.5 \%$ water) to evaluate total insulin content. The amount of insulin in the samples was assessed using Insulin ELISA (EIA) (SPI-bio, Montigny-le-Bretonneux, France).

Subcellular fractionation and protein extraction Subcellular fractionation was performed as described by $\mathrm{Li}$ et al. [19]. Briefly, cells were lysed for $15 \mathrm{~min}$ on ice using a Triton X100 lysis buffer $(50 \mathrm{mmol} / 1 \mathrm{Tris} / \mathrm{HCl}, \mathrm{pH} 7.5,0.5 \%$ Triton $\mathrm{X}-100,137.5 \mathrm{mmol} / \mathrm{l} \mathrm{NaCl}, 10 \%$ glycerol, $1 \mathrm{mmol} / \mathrm{l}$ sodium vanadate, $50 \mathrm{mmol} / \mathrm{l} \mathrm{NaF}, 10 \mathrm{mmol} / 1$ sodium pyrophosphate, $5 \mathrm{mmol} / 1 \mathrm{EDTA}$ and the Protease Inhibitors Cocktail [Sigma, St Louis, MO, USA]). After a $15 \mathrm{~min}$ centrifugation at $12,000 \mathrm{~g}$, the supernatant fraction was collected and stored as 'cytoplasmic fraction'. The pellet was washed and resuspended in Triton X-100 lysis buffer containing $0.5 \%$ SDS. After sonication, the tube was centrifuged at $12,000 \mathrm{~g}$ for $15 \mathrm{~min}$. The supernatant fraction yielded the 'nuclear fraction'. To obtain whole cell extracts, the cells were directly scraped into SDS-containing lysis buffer.

Western blots Protein extracts $(25-50 \mu \mathrm{g})$ were separated on polyacrylamide gels and transferred to poly(vinylidine fluoride) membranes. The membranes were incubated overnight at $4^{\circ} \mathrm{C}$ with primary antibodies. Immunoreactive bands were visualised by chemiluminescence (Amersham Biosciences, Piscataway, NJ, USA) after incubation with horseradish peroxidase-coupled secondary antibodies for $1 \mathrm{~h}$ at room temperature. The antibody against AUF1 (07-260) was purchased from Upstate (Temecula, CA, USA). The antibodies against myeloid cell leukaemia sequence 1 (MCL1 [sc-819]) and lamin B (sc-6216) were purchased from Santa-Cruz Biotechnology (Santa-Cruz, CA, USA). The antibodies against B cell leukaemia/lymphoma 2 (BCL2 [2870]), inhibitor of kappa $\mathrm{B}(\mathrm{I} \kappa \mathrm{B} \alpha ; 4814)$ and phospho-IKB $\alpha$ (2859) were purchased from Cell Signaling Technologies (Danvers, MA, USA). The antibody against actin (MAB1501) was from Chemicon International (Temecula, CA, USA). Finally, the antibody against $\alpha$-tubulin (T5168) was obtained from Sigma (Buchs, Switzerland).

Apoptosis assay For the assessment of the apoptotic activity, MIN6 cells $\left(1 \times 10^{5}\right)$ and human dissociated islet cells plated in 24-well dishes were transiently transfected with plasmids overexpressing AUF1 isoforms or with siRNAs reducing their endogenous level. Apoptosis was assessed 2 days later by staining the cells with Hoechst 33342 (Invitrogen) and 
scoring the cells displaying pyknotic nuclei. The experiments were carried out blindly, and at least 800 cells per condition were analysed.

Immunohistochemistry Transfected MIN6 cells were incubated overnight at $4^{\circ} \mathrm{C}$ with primary antibody directed against cleaved caspase 3 (9661; Cell Signaling). Immunolabelled proteins were visualised by incubating the cells for $1 \mathrm{~h}$ at room temperature with fluorescent secondary antibodies (Invitrogen). Images were obtained by fluorescence microscopy.

Statistical analysis Statistical differences were tested by ANOVA. The experiments including more than two groups were first analysed by ANOVA, and multiple comparisons of the means were then carried out using the post hoc Dunnett's test, with a discriminating $p$ value of 0.05 .

\section{Results}

We first determined the production pattern of AUF1 isoforms in pancreatic beta cells. We found that the mouse insulin-secreting cell line, MIN6, expresses all four AUF1 isoforms. The two larger isoforms, p45 and p42, are the most abundant, while p40 and p37 are less abundantly produced (Fig. 1a). A similar pattern was observed in human pancreatic islets (Fig. 1b) and in the rat insulin-secreting cell line, INS-1E (not shown). Exposure to IL-1 $\beta(10 \mathrm{ng} / \mathrm{ml}$; $5000 \mathrm{U} / \mathrm{ml}$ ) for $24 \mathrm{~h}$, alone or with a mix of cytokines including IL-1 $\beta(0.1 \mathrm{ng} / \mathrm{ml} ; 50 \mathrm{U} / \mathrm{ml}), \mathrm{TNF} \alpha(10 \mathrm{ng} / \mathrm{ml}$; $500 \mathrm{U} / \mathrm{ml})$ and IFN $\gamma(30 \mathrm{ng} / \mathrm{ml} ; 50 \mathrm{U} / \mathrm{ml})$, two conditions that trigger beta cell apoptosis, affected neither the total amount of AUF1 present in MIN6 cells nor the ratio between isoforms (ESM Fig. 1a, b). Similar data were obtained with human islets incubated in the presence of $10 \mathrm{ng} / \mathrm{ml} \mathrm{IL-} \beta$ (ESM Fig. 1c).

We then analysed the subcellular localisation of AUF1 isoforms. As demonstrated by the distribution of specific markers (tubulin and lamin B), our fractionation protocol allows a clear separation between cytosolic and nuclear compartments (Fig. 2a). We found that, under resting conditions, the bulk of $\mathrm{p} 45$ and p 37 is localised in the nucleus, while p40 is detected mainly in the cytosolic fraction. p42 is readily detectable in both fractions and represents the most abundant isoform in the cytosol (ESM Fig. 2a, b). Although, as indicated above, cytokines do not affect the total cellular AUF1 content, exposure to these inflammatory mediators led to redistribution of a fraction of the RNA-binding protein between cellular compartments. Indeed, $24 \mathrm{~h}$ of treatment with the cytokine mix increases AUF1 levels in the cytosolic fraction and decreases those detectable in the nuclear fraction, suggesting activation and translocation of the protein from the a
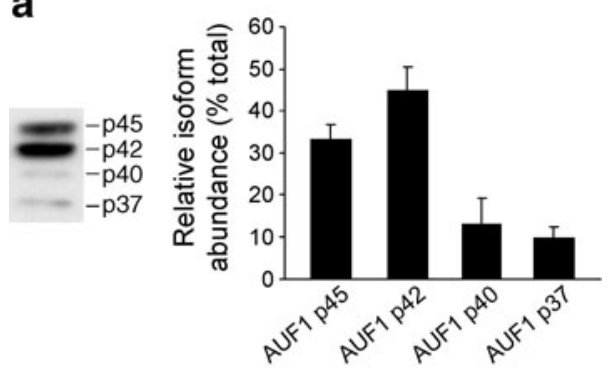

b

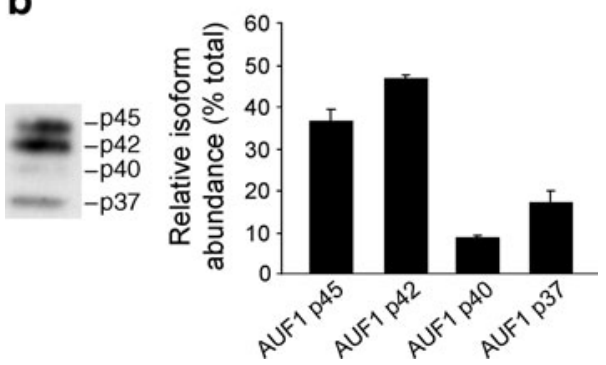

Fig. 1 Abundance of AUF1 isoforms in insulin-secreting cells. Total extracts of MIN6 cells (a) or isolated human pancreatic islets (b) were analysed by western blotting using an antibody recognising all AUF1 isoforms. The bands corresponding to each of the AUF1 isoforms were quantified by densitometric scanning of the films. The relative abundance of each isoform was calculated by dividing the intensity of each band by the signal obtained from all AUF1 isoforms; the results shown are the mean \pm SD of five (MIN6) or three (human islets) independent experiments

nucleus to the cytoplasm (Fig. 2a, b, c). The redistribution of AUF1 isoforms was prevented by a pharmacological inhibitor of the mitogen-activated protein kinase (MAPK), ERK (Fig. 3a, b, c), but not by agents blocking the JNK or p38 kinase pathways (not shown).

To assess whether AUF1 activation contributes to cytokine-mediated beta cell dysfunction, AUF1 isoforms were either overproduced individually in MIN6 cells using specific constructs or silenced by RNA interference. Each of the EGFP-tagged AUF1 constructs was overproduced to comparable levels, and taking into account a transfection efficiency with plasmids of $\sim 30 \%$ (determined by scoring EGFP-positive cells) led to an approximately twofold to threefold increase in the cellular level of each individual isoform (ESM Fig. 3). Exogenously produced AUF1 isoforms displayed a subcellular localisation comparable to the endogenous proteins and were mainly localised in the nucleus (ESM Fig. 3). Silencing of AUF1 isoforms was achieved with siRNAs directed against different regions of the transcripts. We used siRNAs directed against exon 2 (shared by isoforms $\mathrm{p} 45$ and $\mathrm{p} 40$ ), exon 7 (shared by $\mathrm{p} 45$ and $\mathrm{p} 42$ ) or a sequence astride exon 3 and 4 (present in all isoforms) (Fig. 4a). The efficiency of each of the three siRNAs was assessed by western blotting (Fig. 4b, c, d).

We first examined whether changes in the level of AUF1 alter the capacity of pancreatic beta cells to synthesise and 


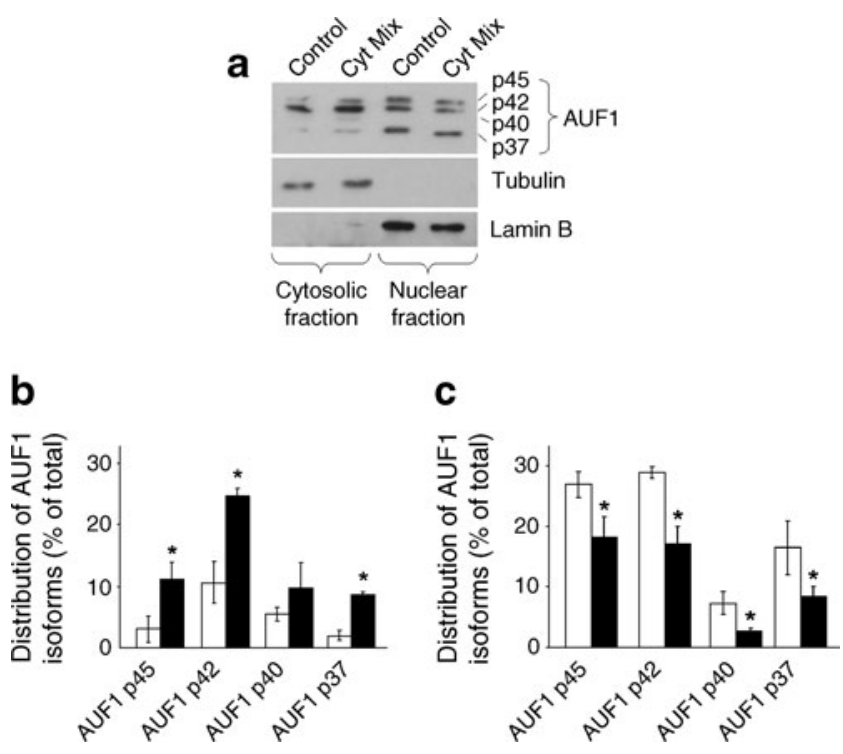

Fig. 2 Impact of proinflammatory cytokines on the subcellular distribution of AUF1 isoforms. a MIN6 cells were incubated for $24 \mathrm{~h}$ in the presence or absence of a mixture of cytokines (Cyt Mix) including IL$1 \beta(0.1 \mathrm{ng} / \mathrm{ml}), \mathrm{TNF} \alpha(10 \mathrm{ng} / \mathrm{ml})$ and IFN $\gamma(30 \mathrm{ng} / \mathrm{ml})$. Cytosolic and nuclear fractions were prepared as described in the methods section and analysed by western blotting using antibodies against AUF1 and against cytosolic (tubulin) and nuclear (lamin B) markers. The figure shows a representative experiment. Quantification of the subcellular distribution of AUF1 isoforms in MIN6 cells incubated in the presence (black bars) or absence (white bars) of proinflammatory cytokines in the cytosolic (b) and in the nuclear compartment (c). The bands corresponding to each AUF1 isoform were quantified by densitometric scanning of the films from three independent experiments. Significantly different from control, ${ }^{*} p<0.05(n=3)$

secrete insulin. Overproduction of each isoform independently did not significantly affect proinsulin mRNA levels (ESM Fig. 4a). Moreover, blocking the production of AUF1 isoforms using siRNAs was not sufficient to restore proinsulin production (ESM Fig. 4b) and insulin content (ESM Fig. $4 c)$ in MIN6 cells treated with IL-1 $\beta$ (10 $\mathrm{ng} / \mathrm{ml})$ for $24 \mathrm{~h}$.

We then assessed whether AUF1 overproduction affects the secretory properties of beta cells. Overproduction of AUF1 isoforms did not influence insulin secretion under basal ( $2 \mathrm{mmol} / \mathrm{l}$ glucose) or stimulated ( $20 \mathrm{mmol} / \mathrm{l}$ glucose) conditions (ESM Fig. 5a). To verify that failure to detect changes in insulin secretion is not caused by the relatively low transfection efficiency, the cells were transiently cotransfected with AUF1-overproducing constructs and with an hGH-encoding plasmid. hGH is specifically targeted to beta cell secretory granules and is co-released with insulin [20], allowing selective monitoring of exocytosis from the transfected cells. AUF1 overproduction affected neither basal nor glucose-induced hGH release, confirming that the RNA-binding protein does not regulate the production of essential components of the beta cell secretory machinery (ESM Fig. 5b).
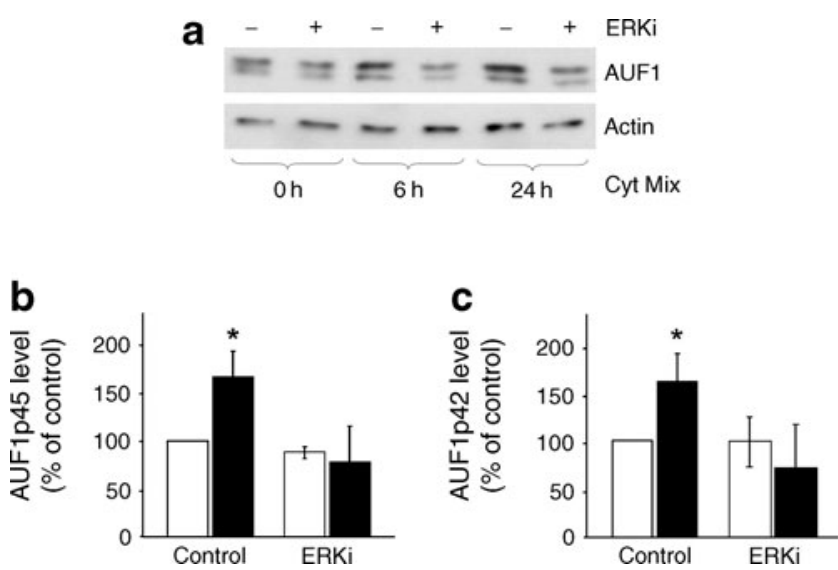

Fig. 3 Subcellular redistribution of AUF1 isoforms can be prevented by inhibitors of ERK. a MIN6 cells were incubated for 0,6 and $24 \mathrm{~h}$ with a mixture of cytokines (Cyt Mix) including IL-1 $\beta(0.1 \mathrm{ng} / \mathrm{ml})$, $\mathrm{TNF} \alpha(10 \mathrm{ng} / \mathrm{ml})$ and IFN $\gamma(30 \mathrm{ng} / \mathrm{ml})$ in the presence $(+)$ or absence (-) of a pharmacological inhibitor of ERK (ERKi; $100 \mu \mathrm{mol} / \mathrm{l})$. Cytosolic fractions were then analysed by western blotting using antibodies against AUF1 and actin. b, c MIN6 cells were incubated for $24 \mathrm{~h}$ in the presence (black bars) or absence (white bars) of the cytokines indicated in (a). The fraction of the two most abundant AUF1 isoforms, p45 (b) and p42 (c), present in the cytosol was quantified by densitometric scanning of the films. The signal obtained in control cells in the absence of the ERK inhibitor was set to $100 \%$. The figure shows the mean $\pm \mathrm{SD}$ from three independent experiments. Significantly different from control, ${ }^{*} p<0.05$

Prolonged exposure of pancreatic beta cells to cytokines sensitises them to apoptosis. We found that overproduction of p40, p42 and p45 isoforms increases the apoptotic rate of MIN6 cells by more than two fold (Fig. 5a). In contrast, p37 had no significant effect on cell survival. Interestingly, the siRNAs directed against AUF1 isoforms reduced caspase 3 activation elicited by cytokines (Fig. 5b) and partially protected the cells from apoptosis (Fig. 5c). We then tested whether the siRNAs directed against AUF1 isoforms improve survival of primary human beta cells in the presence of cytokines. Transfection of human islet cells with siRNAs directed against AUF1 led to a decrease of $\sim 75 \pm 7 \%$ of the mRNA encoding the RNA-binding protein. As was the case for MIN6 cells, blockade of AUF1 production protected human dissociated islet cells from cytokine-induced apoptosis (Fig. 5d). Human islet preparations are not composed exclusively of beta cells. However, taken together with the results obtained with MIN6 cells, these findings indicate that activation of AUF1 is part of the signalling cascades leading to cytokine-mediated beta cell death.

Next, we attempted to determine the molecular mechanisms underlying the effect of AUF1 on beta cell survival. It has been previously demonstrated that AUF1 isoforms can destabilise the mRNAs encoding the anti-apoptotic protein, BCL2 [21]. Western blotting analysis revealed that overproduction of p45 AUF1 results in a significant decrease in the production of BCL2 (Fig. 6a, b). Overproduction of p40 and 


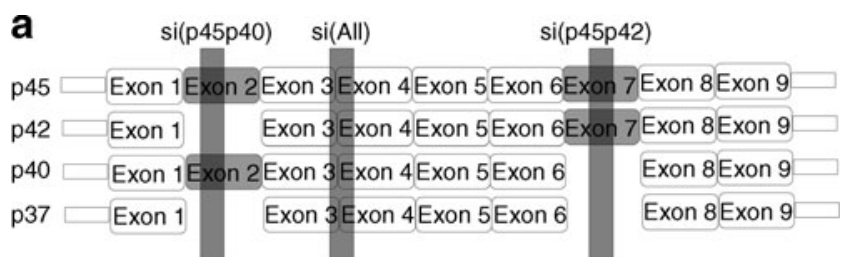

b
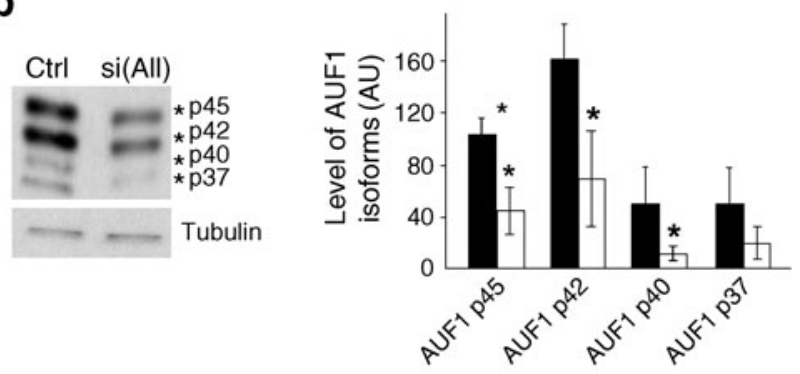

C
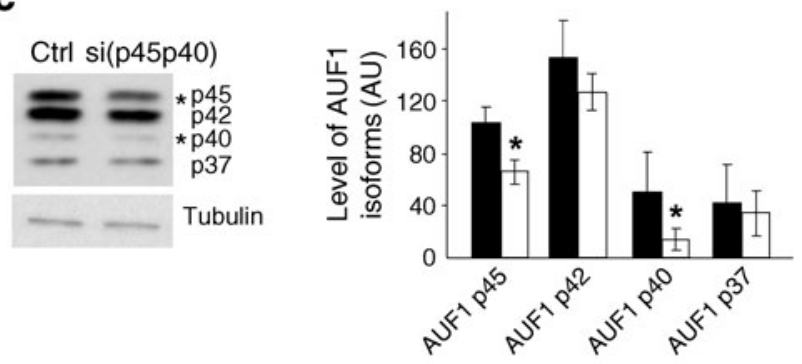

d
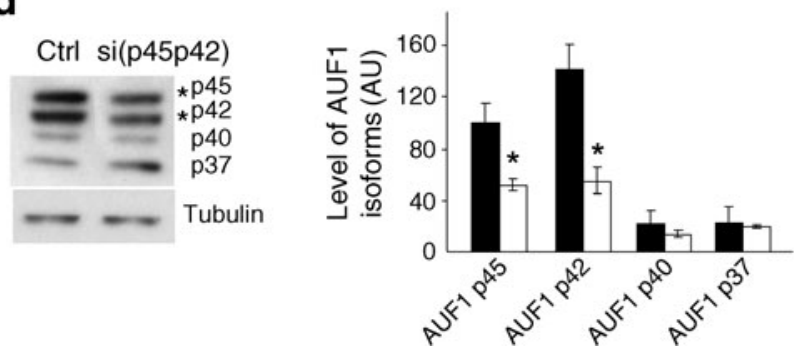

Fig. 4 Silencing of AUF1 isoforms by RNA interference. a Schematic representation of the structure of the four AUF1 isoforms and of the position of the sequences recognised by the different siRNAs. b-d Western blotting of total extracts of MIN6 cells transiently transfected with the three different siRNAs. The figures show a representative experiment. Ctrl, control. The fraction of each AUF1 isoform present in MIN6 cells transfected with control oligonucleotides or with si(All) (b), si(p45p40) (c) and si(p45p42) (d) was quantified by densitometric scanning of the films. Mean \pm SD values from three to four independent experiments are shown. Significantly different from control, $* p<0.05$. AU, arbitrary units

p42 displayed a similar tendency, but, possibly because of the relatively low transfection efficiency obtained with plasmids, this did not reach statistical significance. Transfection of the cells with the siRNAs that reduce AUF1 production (all of them block p45) restored BCL2 levels in IL-1 $\beta$ treated cells (Fig. 6c, d). This effect is potentially linked to the increase in $\mathrm{Bcl} 2 \mathrm{mRNA}$ stability observed upon AUF1 silencing (ESM Fig. 6 top panel). These findings may
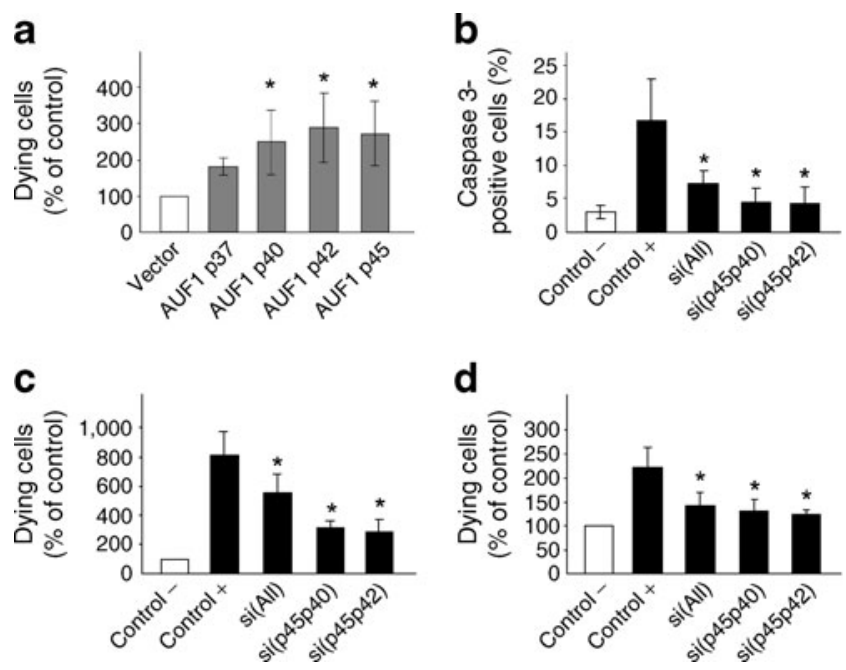

Fig. 5 Involvement of AUF1 isoforms in cytokine-mediated apoptosis. a MIN6 cells were transiently transfected with plasmids encoding individual AUF1 isoforms. Two days later, the cells were stained with Hoechst 33342, and the fraction of them displaying pyknotic nuclei was scored. The figure shows the mean \pm SD from six independent experiments. Cell death in cells transfected with an empty EGFP plasmid (vector) was $4 \pm 2 \%$. The value obtained under control conditions (vector) in each experiment was set to $100 \%$. Significantly different from control conditions, $* p<0.05(n=6)$. b MIN6 cells were transfected with siGFP (Control) or the indicated AUF1 siRNAs. The day after, the cells were incubated in the absence (white bar) or presence (black bars) of a mixture of cytokines including IL- $1 \beta$ $(0.1 \mathrm{ng} / \mathrm{ml}), \mathrm{TNF} \alpha(10 \mathrm{ng} / \mathrm{ml})$ and $\mathrm{IFN} \gamma(30 \mathrm{ng} / \mathrm{ml})$. The cells were then stained with an antibody specifically recognising the activated form of caspase 3. Cell death in siGFP-transfected cells incubated in the absence of cytokines was $3 \pm 2 \%$. Significantly different from siGFP-transfected cells incubated with cytokines (Control+), ${ }^{*} p<0.05$ $(n=4)$. c MIN6 cells transfected with siGFP or AUF1 siRNAs were incubated with (black bars) or without (white bar) the mixture of cytokines indicated above. The fraction of cells displaying pyknotic nuclei was determined by Hoechst 33342 staining. Cell death in siGFPtransfected cells incubated in the absence of cytokines was $3 \pm 2 \%$. Significantly different from siGFP-transfected cells incubated with cytokines $($ Control +$),{ }^{*} p<0.05(n=4)$. d Human pancreatic islet cells were transfected with a siRNA against GFP (Control) or with the indicated AUF1 siRNAs. The day after, the cells were incubated in the presence (black bars) or absence of IL-1 $\beta(0.1 \mathrm{ng} / \mathrm{ml}), \mathrm{TNF} \alpha$ $(10 \mathrm{ng} / \mathrm{ml})$ and $\operatorname{IFN} \gamma(30 \mathrm{ng} / \mathrm{ml})$ for $24 \mathrm{~h}$. The fraction of cells undergoing apoptosis was estimated by scoring the cells displaying pyknotic nuclei. Cell death in control cells was $5 \pm 2 \%$. Significantly different from siGFP-transfected cells incubated with cytokines $($ Control +$),{ }^{*} p<0.05(n=3)$

explain, at least in part, the protective effect of the siRNAs on beta cell survival. Recently, MCL1, another antiapoptotic protein belonging to the BCL2 family, was shown to be downregulated on prolonged exposure of beta cells to proinflammatory cytokines and to be involved in pancreatic beta cell apoptosis [22]. Interestingly, we found that transfection of MIN6 cells with the siRNAs that diminish AUF1 production restore MCL1 levels in IL-1 $\beta$-treated cells (Fig. 6c, e). In contrast with BCL2, this effect was not 
a


C
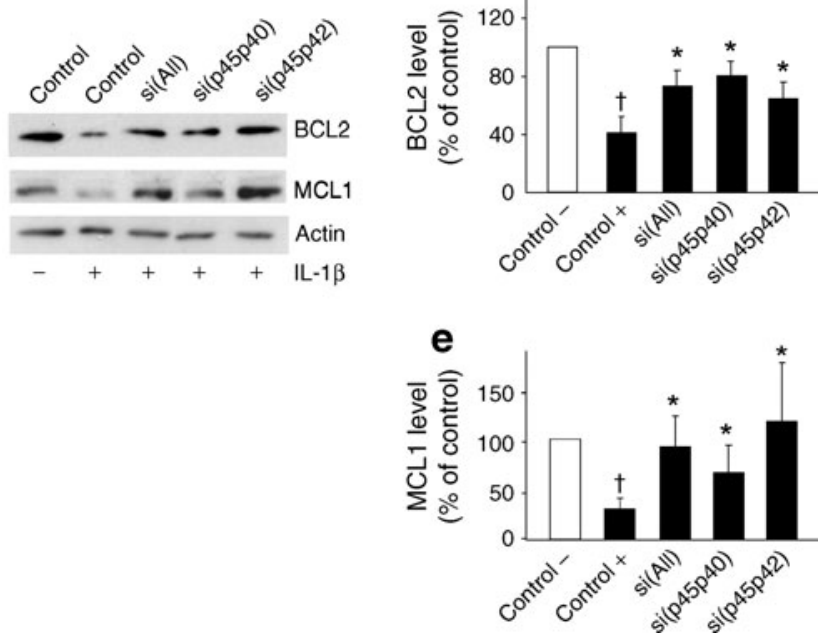

Fig. 6 Impact of AUF1 on the production of the anti-apoptotic proteins BCL2 and MCL1. a MIN6 cells were transfected with an empty plasmid (vector) or with plasmids driving the production of each of the isoforms of AUF1. BCL2 and actin production were assessed by western blotting. The figure shows a representative experiment out of five. b Quantification of the impact of the overproduction of AUF1 isoforms on BCL2 production by densitometric scanning of the films. The results are means \pm SD from five independent experiments. Significantly different $\left({ }^{*} p<0.05\right)$ from the empty vector. c MIN6 cells were transfected with a siRNA against GFP (Control) or with the indicated AUF1 siRNAs. The day after, the cells were incubated for $24 \mathrm{~h}$ with $(+)$ or without $(-)$ IL-1 $\beta(10 \mathrm{ng} / \mathrm{ml})$. BCL2, MCL1 and actin production were assessed by western blotting. Quantification of the impact of AUF1 silencing on BCL2 (d) and MCL1 (e) production by densitometric scanning of the films. The results are means \pm SD from four independent experiments. Significantly different from Control$\left({ }^{\dagger} p<0.05\right)$ and from Control+ $\left({ }^{*} p<0.05\right)$

related to changes in mRNA stability (ESM Fig. 6 middle panel).

Chronic activation of the nuclear factor- $\mathrm{KB}(\mathrm{NF} \kappa \mathrm{B})$ pathway plays a central role in cytokine-mediated beta cell death [23]. Since silencing of AUF1 prevents apoptosis triggered by cytokines, we assessed whether reduction of the level of the RNA-binding protein affects this important signalling pathway. We discovered that phosphorylation of IkB $\alpha$ elicited by a mix of cytokines, an essential step in the activation of the $\mathrm{NF} \kappa \mathrm{B}$ pathway, is strongly impaired in cells in which AUF1 isoforms are downregulated (Fig. 7a, b). In contrast, phosphorylation of JNK, another signalling pathway playing a
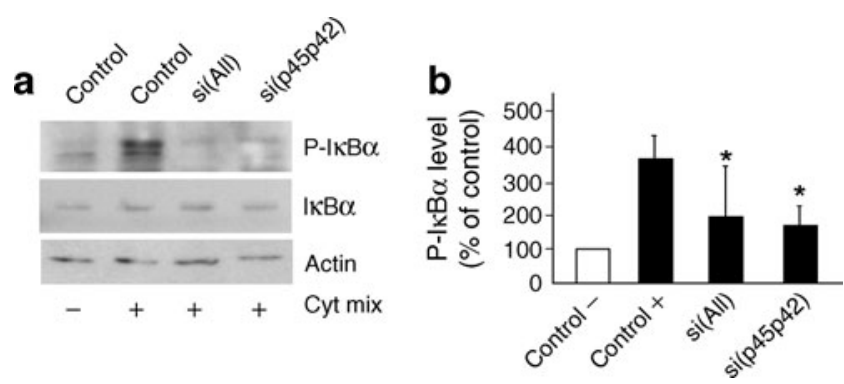

Fig. 7 Silencing of AUF1 attenuates the induction of the NFKB pathway elicited by cytokines. a MIN6 cells were transfected with a siRNA against GFP (Control) or with the indicated AUF1 siRNAs. The day after, the cells were incubated for $4 \mathrm{~h}$ with $(+)$ or without $(-)$ a mix of cytokines (Cyt mix) including IL-1 $\beta(0.1 \mathrm{ng} / \mathrm{ml}), \mathrm{TNF} \alpha(10 \mathrm{ng} / \mathrm{ml}$ and IFN $\gamma(30 \mathrm{ng} / \mathrm{ml})$. Phospho-I $\mathrm{K} \mathrm{B} \alpha(\mathrm{P}-\mathrm{I} \kappa \mathrm{B} \alpha), \mathrm{I} \kappa \mathrm{B} \alpha$ and actin production were assessed by western blotting. The figure shows a representative experiment out of five. b Quantification of the impact of the silencing of AUF1 during cytokine exposure on phospho-IKB $\alpha$ production by densitometric scanning of the films. The results are expressed as means \pm SD from five independent experiments

central role in cytokine-mediated apoptosis, was unaffected (data not shown).

Many of the deleterious effects triggered by chronic $\mathrm{NF} \kappa \mathrm{B}$ activation in insulin-secreting cells result from the induction of inducible nitric oxide synthase (iNOS) [24] and of several chemokines [25] thought to elicit an inflammatory cascade that promote the development of type 1 diabetes [1]. In agreement with the data described above, we found that the induction of iNOS elicited by $6 \mathrm{~h}$ of IL- $1 \beta$ treatment is significantly attenuated in MIN6 cells transfected with the siRNAs against AUF1 (Fig. 8a). Moreover, the rise in two chemokines containing an AUF1-binding motif in their 3'-UTR, chemokine (C-C motif) ligand 2/monocyte chemotactic protein 1 (CCL2/MCP1) and chemokine (C-X-C motif) ligand 2/macrophage inhibitor protein 2 (CXCL2/MIP2) [9], elicited by proinflammatory cytokines was significantly diminished upon blockade of AUF1 production (Fig. 8b, c). Taken together, these findings point to an important contribution of AUF1 in NFKB-induced inflammatory reactions, occurring in the initial phases of type 1 diabetes.

\section{Discussion}

The initial phases of type 1 diabetes are characterised by a cytokine-mediated inflammatory reaction directed against pancreatic islets, which culminates in a progressive loss of beta cells. Proinflammatory cytokines released by T lymphocytes and macrophages invading the islets and by the endocrine cells themselves alter beta cell gene expression by affecting the activity of important transcription factors leading to impairment of key signalling pathways. The involvement of transcription factors such as NFKB, signal transducers and activators of transcription 1 (STAT1) and activator protein 1 

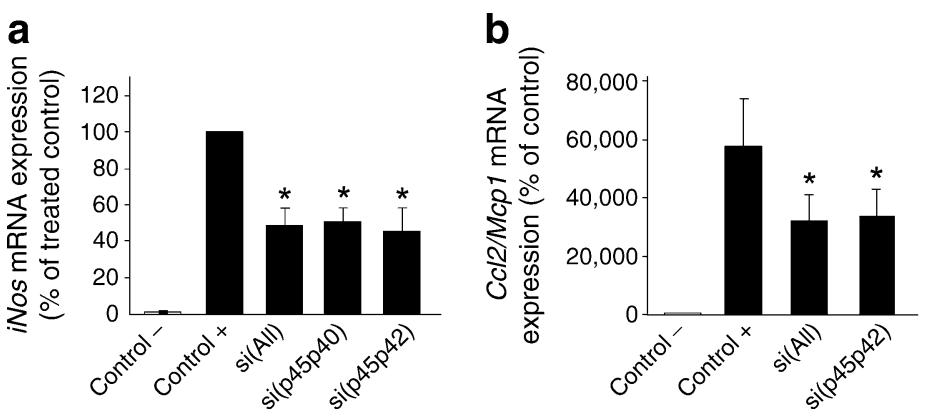

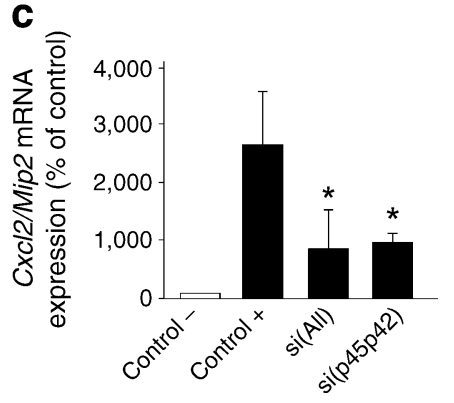

Fig. 8 Silencing of AUF1 attenuates the induction of chemokines and iNOS elicited by cytokines. a MIN6 cells were transfected with a siRNA against GFP (Control) or with the indicated AUF1 siRNAs. Two days later, the cells were treated with (black bars) or without (white bar) IL-1 $\beta(10 \mathrm{ng} / \mathrm{ml})$ for $6 \mathrm{~h}$. The level of the $i N o s$ mRNA was determined by qRT-PCR. The values obtained for control cells incubated in the presence of IL- $1 \beta$ was set to $100 \%$. Significantly different from control cells incubated with IL-1 $\beta,{ }^{*} p<0.05(n=4)$. b and $\mathbf{c}$
MIN6 cells were transfected with a siRNA against GFP (Control) or with the indicated AUF1 siRNAs. Two days later, the cells were treated for $8 \mathrm{~h}$ with (black bars) or without (white bar) a mix of cytokines including IL-1 $\beta(0.1 \mathrm{ng} / \mathrm{ml}), \mathrm{TNF} \alpha(10 \mathrm{ng} / \mathrm{ml})$ and $\mathrm{IFN} \gamma(30 \mathrm{ng} / \mathrm{ml})$. The level of Ccl2/Mcp1 (b) and Cxcl2/Mip2 (c) mRNAs were determined by qRT-PCR. The values obtained for control cells were set to $100 \%$. Significantly different from control cells incubated with cytokines, ${ }^{*} p<0.05(n=4-5)$
(AP-1) in cytokine-mediated beta cell damage has been extensively investigated [26]. However, it is becoming increasingly clear that other regulatory molecules, acting upstream or downstream of transcription factors, make an important contribution to the control of gene expression. This is the case for RNA-binding proteins, such as AUF1, that bind to specific regions of their target mRNAs, thereby influencing their stability and translation. There is mounting evidence that AUF1 plays a central role in inflammation. Indeed, AUF1-binding motifs are present in the messengers of important inflammatory mediators such as the cytokines, $\mathrm{TNF} \alpha$ and granulocyte-macrophage colony-stimulating factor [27, 28], the chemokines, CXCL2/MIP2 and CCL2/ MCP1 [9], and those of some interleukins [29, 30]. Moreover, AUF1 affects the production of important components of the signalling pathways initiated by cytokines [31, 32].

Here, we demonstrate that beta cells produce four AUF1 isoforms that are differentially distributed between the cytosolic and nuclear compartments. The localisation of AUF1 can be influenced by a variety of factors including: the presence or absence of exons containing nuclear localisation signals [33, 34]; interaction with transporters [35] or chaperones [36, 37]; protein ubiquitination [13]; and phosphorylation of specific residues [7, 38]. At steady-state, most AUF1 isoforms accumulate in the nucleus but are partially relocalised upon exposure of insulin-secreting cells to proinflammatory cytokines. The precise mechanisms underlying the nucleocytoplasmic shuttling of the protein have not yet been defined. However, since the effect of the cytokines can be prevented by inhibiting the MAPK, ERK, this process is likely to involve the phosphorylation of one or more residues of AUF1. In agreement with this hypothesis, nuclear ERK has recently been reported to stimulate nucleocytoplasmic translocation and activation of AUF1p42 [39]. In contrast, in our hands, neither JNK nor p38 MAPK appeared to affect the localisation of AUF1 isoforms.

Prolonged exposure of beta cells to cytokines sensitises them to apoptosis. Overproduction of p40, p42 and p45 AUF1 isoforms mimicked the effect of the cytokines and led to a similar impact on beta cell survival. Moreover, blockade of AUF1 production protected the beta cells from apoptosis elicited by the cytokines, indicating that this RNA-binding protein contributes to the deleterious events that lead to death of insulin-secreting cells upon chronic exposure to these inflammatory mediators. We were able to partially elucidate the mechanisms through which AUF1 affects beta cell survival. Indeed, the reduction of the production of two anti-apoptotic proteins, BCL2 and MCL1, elicited by cytokines was efficiently prevented by silencing AUF1. Both of these anti-apoptotic proteins have been shown to play a role in beta cell survival $[22,40]$. The effect of AUF1 on BCL2 may be mediated, at least in part, by direct association of the RNA-binding protein to the AU-rich elements present in the 3 '-UTR of Bcl2 mRNA, resulting in messenger destabilisation $[21,41]$. Indeed, we observed that silencing of AUF1 results in a small but significant increase in $B c l 2$ mRNA stability. So far, consensus sequences for AUF1 binding have not been identified in the Mcll mRNA. Moreover, blockade of AUF1 production by RNA interference appears not to influence $M c l 1$ mRNA stability. Thus the level of this anti-apoptotic protein is likely to be modulated indirectly through the modification of other regulatory factors.

Our results suggest that one of the key signalling pathways involved in beta cell apoptosis is also regulated by AUF1. The transcription factor NFKB contributes to cytokine-mediated beta cell dysfunction and to the development of type 1 diabetes. Indeed, Eldor and collaborators showed that mice 
producing an NFKB repressor are protected from diabetes induced by streptozotocin injections [42]. Recently, inhibition of AUF1 was reported to prevent lipopolysaccharideinduced $N F K B$ signalling in monocytes and macrophages [43]. In agreement with these data, we found that phosphorylation of $I \kappa B \alpha$ elicited by a mix of cytokines, an essential step in the activation of the NFKB pathway, is strongly impaired in cells in which AUF1 isoforms are downregulated. The attenuation of the NFKB signalling resulted in reduced induction of iNOS and diminished production of the chemokines, CXCL2/MIP2 and CCL2/MCP1. In other cell types, AUF1 destabilises iNos mRNA [17]. Although our data did not reach statistical significance, in MIN6 cells treated with siRNAs directed against AUF1, iNos mRNA tended to be more stable (ESM Fig. 6 bottom panel). Therefore we cannot rule out the possibility that a similar mechanism also takes place in beta cells. However, even if present, in MIN6 cells the effect on mRNA stability appears to have less impact on iNOS levels than the attenuation of the NF $\kappa \mathrm{B}$ signalling. NO production plays a pivotal role in the deleterious action exerted by proinflammatory cytokines on beta cells [44]. Therefore, at least part of the protective effect of AUF1 silencing can probably be attributed to the smaller induction of iNOS. Chemokines such as CXCL2/ MIP2 and CCL2/MCP1 released by beta cells chronically exposed to cytokines are thought to constitute an immunogenic signal that favours the recruitment of immune cells and contributes to the amplification of the inflammatory reaction [1]. Our findings indicate that activation of AUF1 can modulate this inflammatory signal that promotes the development of type 1 diabetes.

In this study, we highlighted an important contribution of AUF1 to the deleterious effects of proinflammatory cytokines on beta cell survival. We were able to partially dissect the events leading to AUF1 redistribution and to characterise the signalling cascades downstream of the activation of the RNA-binding protein. Future studies need to precisely identify the molecular mechanisms regulating the nucleocytoplasmic shuttling of AUF1 in cytokine-treated beta cells and to definitively assess its contribution to the development of type 1 diabetes. Our findings suggest that a better knowledge of the role played by AUF1 and other RNA-binding proteins in the islet inflammatory reaction could potentially open the way to new strategies to prevent beta cell death and the development of type 1 diabetes.

Acknowledgements This work was supported by the Swiss National Science Foundation grant 31003A-127254 (to R. Regazzi).

Contribution statement ER generated the researched and analysed the data, wrote the manuscript and approved its final version. SG generated the researched and analysed the data, critically reviewed the manuscript and approved its final version. AP contributed to interpretation of the data, critically reviewed the manuscript and approved its final version. RR conceived and designed the experiments, analysed the research data, wrote the manuscript and approved its final version.

Duality of interest The authors declare that there is no duality of interest associated with this manuscript.

\section{References}

1. Eizirik DL, Colli ML, Ortis F (2009) The role of inflammation in insulitis and beta-cell loss in type 1 diabetes. Nat Rev Endocrinol 5:219-226

2. Donath MY, Boni-Schnetzler M, Ellingsgaard H, Ehses JA (2009) Islet inflammation impairs the pancreatic beta-cell in type 2 diabetes. Physiology (Bethesda) 24:325-331

3. Malter JS (1989) Identification of an AUUUA-specific messenger RNA binding protein. Science 246:664-666

4. Shyu AB, Wilkinson MF (2000) The double lives of shuttling mRNA binding proteins. Cell 102:135-138

5. Pinol-Roma S, Dreyfuss G (1992) Shuttling of pre-mRNA binding proteins between nucleus and cytoplasm. Nature 355:730-732

6. Nakamaki T, Imamura J, Brewer G, Tsuruoka N, Koeffler HP (1995) Characterization of adenosine-uridine-rich RNA binding factors. J Cell Physiol 165:484-492

7. Zhang W, Wagner BJ, Ehrenman K et al (1993) Purification, characterization, and cDNA cloning of an AU-rich element RNA-binding protein, AUF1. Mol Cell Biol 13:7652-7665

8. Misquitta CM, Chen T, Grover AK (2006) Control of protein expression through mRNA stability in calcium signalling. Cell Calcium 40:329-346

9. Bhattacharya S, Giordano T, Brewer G, Malter JS (1999) Identification of AUF-1 ligands reveals vast diversity of early response gene mRNAs. Nucleic Acids Res 27:1464-1472

10. Kiledjian M, DeMaria CT, Brewer G, Novick K (1997) Identification of AUF1 (heterogeneous nuclear ribonucleoprotein D) as a component of the alpha-globin mRNA stability complex. Mol Cell Biol 17:4870-4876

11. Wagner BJ, DeMaria CT, Sun Y, Wilson GM, Brewer G (1998) Structure and genomic organization of the human AUF1 gene: alternative pre-mRNA splicing generates four protein isoforms. Genomics 48:195-202

12. Zucconi BE, Ballin JD, Brewer BY et al (2010) Alternatively expressed domains of AU-rich element RNA-binding protein 1 (AUF1) regulate RNA-binding affinity, RNA-induced protein oligomerization, and the local conformation of bound RNA ligands. J Biol Chem 285:39127-39139

13. Laroia G, Schneider RJ (2002) Alternate exon insertion controls selective ubiquitination and degradation of different AUF1 protein isoforms. Nucleic Acids Res 30:3052-3058

14. Wilson GM, Lu J, Sutphen K et al (2003) Phosphorylation of p40AUF1 regulates binding to A+U-rich mRNA-destabilizing elements and protein-induced changes in ribonucleoprotein structure. J Biol Chem 278:33039-33048

15. Lilla V, Webb G, Rickenbach K et al (2003) Differential gene expression in well-regulated and dysregulated pancreatic beta-cell (MIN6) sublines. Endocrinology 144:1368-1379

16. Merglen A, Theander S, Rubi B, Chaffard G, Wollheim CB, Maechler P (2004) Glucose sensitivity and metabolism-secretion coupling studied during two-year continuous culture in INS-1E insulinoma cells. Endocrinology 145:667-678

17. Pautz A, Linker K, Altenhofer S et al (2009) Similar regulation of human inducible nitric-oxide synthase expression by different 
isoforms of the RNA-binding protein AUF1. J Biol Chem 284:2755-2766

18. Abderrahmani A, Steinmann M, Plaisance V et al (2001) The transcriptional repressor REST determines the cell-specific expression of the human MAPK8IP1 gene encoding IB1 (JIP-1). Mol Cell Biol 21:7256-7267

19. Li Y, Y-c B, Misawa Y, Xue Y, Rekosh D, Hammarskjold M-L (2006) An intron with a constitutive transport element is retained in a Tap messenger RNA. Nature 443:234-237

20. Varadi A, Tsuboi T, Rutter GA (2005) Myosin Va transports dense core secretory vesicles in pancreatic MIN6 beta-cells. Mol Biol Cell 16:2670-2680

21. Lapucci A, Donnini M, Papucci L et al (2002) AUF1 Is a bcl-2 A + U-rich element-binding protein involved in bcl-2 mRNA destabilization during apoptosis. J Biol Chem 277:16139-16146

22. Allagnat F, Cunha D, Moore F, Vanderwinden JM, Eizirik DL, Cardozo AK (2011) Mcl-1 downregulation by pro-inflammatory cytokines and palmitate is an early event contributing to beta-cell apoptosis. Cell Death Differ 18:328-337

23. Thomas HE, Angstetra E, Fernandes RV et al (2005) Perturbations in nuclear factor-[kappa]B or c-Jun N-terminal kinase pathways in pancreatic beta cells confer susceptibility to cytokine-induced cell death. Immunol Cell Biol 84:20-27

24. Marks-Konczalik J, Chu SC, Moss J (1998) Cytokine-mediated transcriptional induction of the human inducible nitric oxide synthase gene requires both activator protein 1 and nuclear factor kappaB-binding sites. J Biol Chem 273:22201-22208

25. Thompson WL, van Eldik LJ (2009) Inflammatory cytokines stimulate the chemokines CCL2/MCP-1 and CCL7/MCP-3 through NFkB and MAPK dependent pathways in rat astrocytes [corrected]. Brain Res 1287:47-57

26. Cnop M, Welsh N, Jonas JC, Jorns A, Lenzen S, Eizirik DL (2005) Mechanisms of pancreatic beta-cell death in type 1 and type 2 diabetes: many differences, few similarities. Diabetes 54(Suppl 2): S97-S107

27. Lal A, Mazan-Mamczarz K, Kawai T, Yang X, Martindale JL, Gorospe M (2004) Concurrent versus individual binding of HuR and AUF1 to common labile target mRNAs. EMBO J 23:3092-3102

28. Lu J-Y, Sadri N, Schneider RJ (2006) Endotoxic shock in AUF1 knockout mice mediated by failure to degrade proinflammatory cytokine mRNAs. Genes Dev 20:3174-3184

29. Sarkar S, Sinsimer KS, Foster RL, Brewer G, Pestka S (2008) AUF1 isoform-specific regulation of anti-inflammatory IL10 expression in monocytes. J Interferon Cytokine Res 28:679-692

30. Palanisamy V, Park NJ, Wang J, Wong DT (2008) AUF1 and HuR proteins stabilize interleukin-8 mRNA in human saliva. J Dent Res $87: 772-776$
31. Pautz A, Art J, Hahn S, Nowag S, Voss C, Kleinert H (2010) Regulation of the expression of inducible nitric oxide synthase. Nitric Oxide 23:75-93

32. Sadri N, Schneider RJ (2009) Auf1/Hnrnpd-deficient mice develop pruritic inflammatory skin disease. J Invest Dermatol 129:657-670

33. Sarkar B, Lu JY, Schneider RJ (2003) Nuclear import and export functions in the different isoforms of the AUF1/heterogeneous nuclear ribonucleoprotein protein family. J Biol Chem 278:20700 20707

34. Suzuki M, Iijima M, Nishimura A, Tomozoe Y, Kamei D, Yamada M (2005) Two separate regions essential for nuclear import of the hnRNP D nucleocytoplasmic shuttling sequence. FEBS J 272:3975-3987

35. He C, Schneider R (2006) 14-3-3[sigma] is a p37 AUF1-binding protein that facilitates AUF1 transport and AU-rich mRNA decay. EMBO J 25:3823-3831

36. Knapinska AM, Gratacos FM, Krause CD et al (2011) Chaperone Hsp27 modulates AUF1 proteolysis and AU-rich elementmediated mRNA degradation. Mol Cell Biol 31:1419-1431

37. Arao Y, Kuriyama R, Kayama F, Kato S (2000) A nuclear matrixassociated factor, SAF-B, interacts with specific isoforms of AUF1/hnRNP D. Arch Biochem Biophys 380:228-236

38. Fawal M, Armstrong F, Ollier S et al (2006) A "liaison dangereuse" between AUF1/hnRNPD and the oncogenic tyrosine kinase NPMALK. Blood 108:2780-2788

39. Zhai B, Yang H, Mancini A, He Q, Antoniou J, Di Battista JA (2010) Leukotriene B(4) BLT receptor signaling regulates the level and stability of cyclooxygenase-2 (COX-2) mRNA through restricted activation of Ras/Raf/ERK/p42 AUF1 pathway. J Biol Chem 285:23568-23580

40. Gurzov EN, Eizirik DL (2011) Bcl-2 proteins in diabetes: mitochondrial pathways of beta-cell death and dysfunction. Trends Cell Biol 21:424-431

41. Ishimaru D, Zuraw L, Ramalingam S et al (2010) Mechanism of regulation of bcl-2 mRNA by nucleolin and A+U-rich elementbinding factor 1 (AUF1). J Biol Chem 285:27182-27191

42. Eldor R, Yeffet A, Baum K et al (2006) Conditional and specific NF-kappaB blockade protects pancreatic beta cells from diabetogenic agents. Proc Natl Acad Sci USA 103:5072-5077

43. Sarkar S, Han J, Sinsimer KS et al (2011) RNA-binding protein AUF1 regulates lipopolysaccharide-induced IL10 expression by activating IkappaB kinase complex in monocytes. Mol Cell Biol 31:602-615

44. Hughes KJ, Chambers KT, Meares GP, Corbett JA (2009) Nitric oxides mediates a shift from early necrosis to late apoptosis in cytokine-treated \{beta\}-cells that is associated with irreversible DNA damage. Am J Physiol Endocrinol Metab 297:E1187-E1196 